\title{
Endoscopic Full-Thickness Resection of a Colonic Lateral Spreading Tumor
}

\author{
Ana-Maria Bucalau ${ }^{\mathrm{a}} \quad$ Arnaud Lemmers $^{\mathrm{a}}$ Marianna Arvanitakis $^{\mathrm{a}}$ Daniel Blero $^{\mathrm{b}}$ \\ Horst Neuhaus ${ }^{c}$ \\ aDepartment of Gastroenterology, Hepatopancreatology and Digestive Oncology, Erasme Hospital, Université Libre \\ de Bruxelles, Brussels, and b Department of Gastroenterology, ISPPC Charleroi, Charleroi, Belgium; ' Department of \\ Internal Medicine, Evangelisches Krankenhaus Düsseldorf, Düsseldorf, Germany
}

\section{Keywords}

Full-thickness resection · Endoscopy · Adenoma .

Over-the-scope clip

\begin{abstract}
The Full-Thickness Resection Device (FTRD; Ovesco Endoscopy, Tübingen, Germany) combines endoscopic full-thickness resection (EFTR) of gastrointestinal lesions with closure and cutting of the tissue in one integrated procedure. It provides en-bloc resection with an integral wall specimen for histopathological evaluation. This resection technique is partially filling of the gaps between the current procedures of choice in endoscopy (endoscopic mucosal resection and endoscopic submucosal dissection) and surgery. We present the case of an EFTR procedure performed for a periappendicular lateral spreading tumor.

๑) 2018 S. Karger AG, Basel
\end{abstract}

\section{Background}

Endoscopic mucosal resection (EMR) and endoscopic submucosal dissection (ESD) are the current procedures of choice for the treatment of flat colorectal adenoma and early cancers. ESD may be preferred in lesions suspected to harbor superficial submucosal invasive cancer and reduce the risk of recurrent adenoma in cases of piecemeal EMR [1,2]. However, complication rates (i.e., perforation and bleeding) and incomplete en-bloc resections are significant issues $[3,4]$. Recurrent adenomas and nonlifting lesions remain a challenge regardless of the technique used. The purpose of endoscopic full-thickness resection (EFTR) is to resect lesions that are difficult to lift by submucosal injection, with simultaneous closure of the colon wall defect and provision of an adequate histological specimen.

\section{KARGER}

(C) 2018 S. Karger AG, Basel

E-Mail karger@karger.com

www.karger.com/ddi
Ana-Maria Bucalau

Erasme Hospital

Route de Lennik 808, BE-1070 Brussels (Belgium)

E-Mail Ana-Maria.Bucalau@erasme.ulb.ac.be 


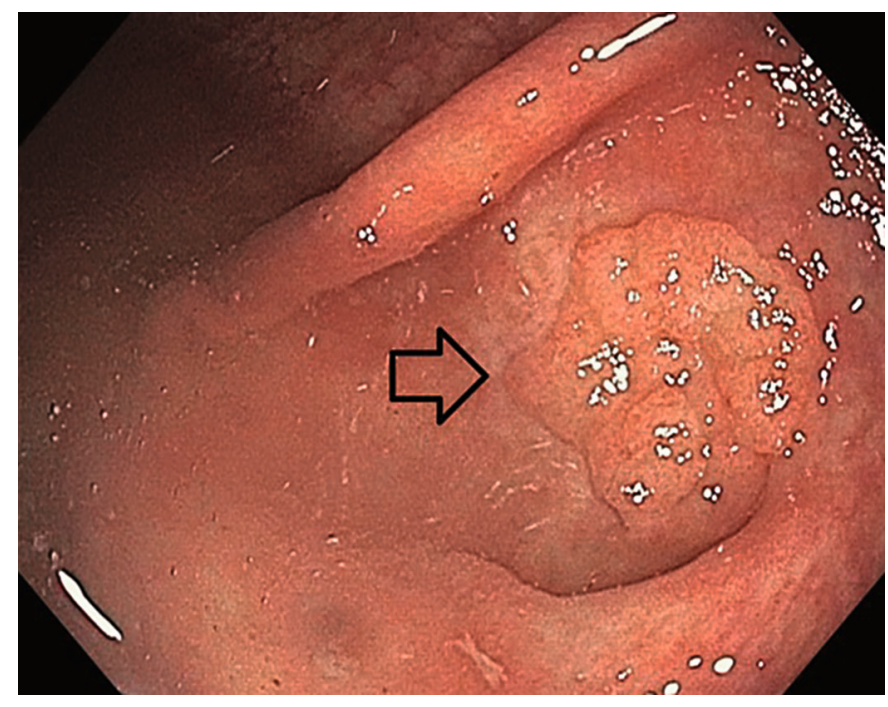

Fig. 1. Periappendicular LST (Paris IIa), white light.

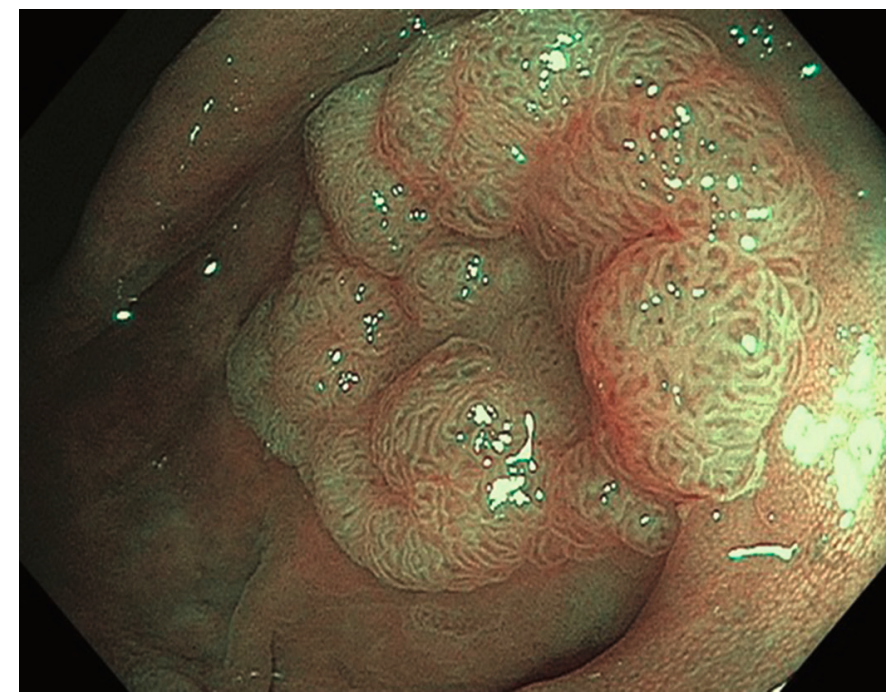

Fig. 2. Periappendicular LST: granular and homogenous in narrow band imaging (NICE type 2).
Fig. 3. FTRD components (with kind permission of Ovesco Endoscopy): (1) cap with preloaded snare; (2) 14-mm over-thescope clip; (3) endoscope sleeve with fixation tapes (3a); (4) hand wheel; (5) integrated polyfile HF snare with thin diameter $(0.2$ $\mathrm{mm})$; (6) snare safety lock, marked with "2" for 2 nd procedure step (resection after clipping).

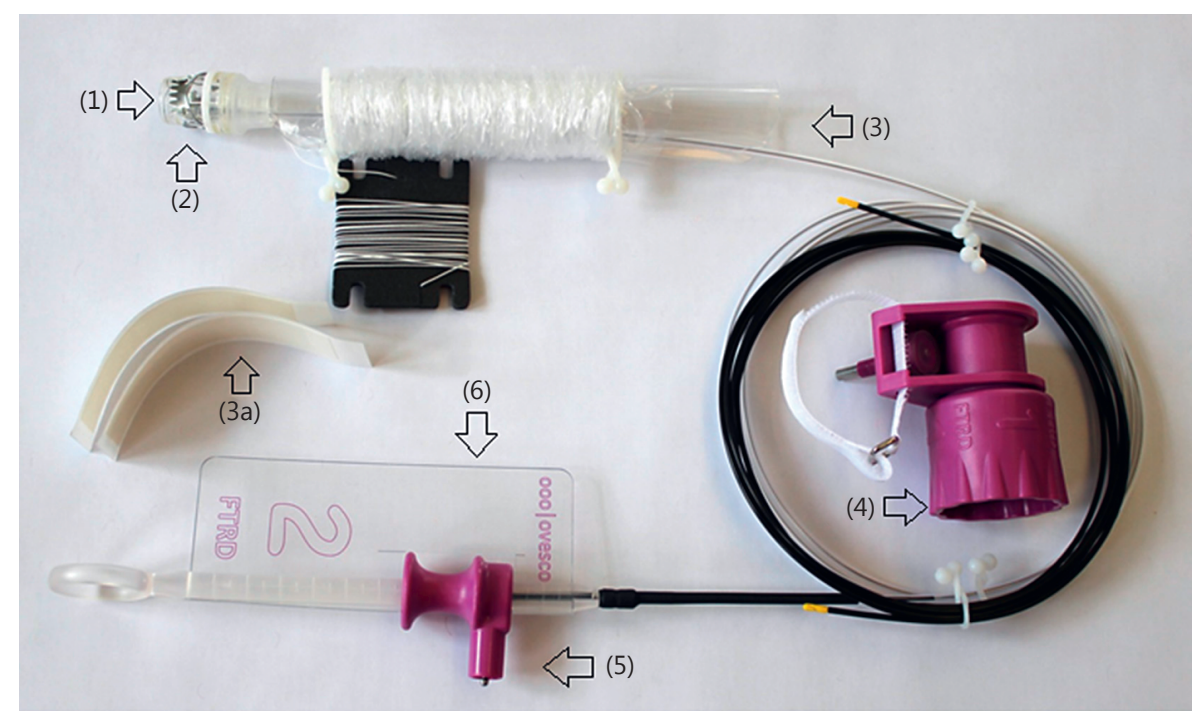

\section{Materials and Methods}

We present the case of a 54-year-old woman with a personal history of 3 EMR sessions for a cecal polyp and a family history of colorectal cancer. A recent colonoscopy showed a periappendicular lateral spreading tumor (LST) that was granular and homogenous (Paris IIa, NICE type 2; Fig. 1, 2), with a nonlifting indication due to severe fibrosis. The biopsies revealed a tubulovillous adenoma with low-grade dysplasia. After having obtained informed consent, she was scheduled for a colonoscopy with full-thickness resection of the LST using the over-the-scope clip device (FullThickness Resection Device, FTRD; Ovesco Endoscopy, Tübingen, Germany). This is a live endoscopy case that was presented during the 35th GEEW 2017, Brussels, Belgium (Video 1).

Endoscopic Full-Thickness Resection of a Colonic Lateral Spreading Tumor
The device presented here (FTRD, Ovesco Endoscopy) consists of a 23-mm cap carrying a modified $14-\mathrm{mm}$ over-the-scope clip with additional lateral teeth for improved tissue hold. A monofilament snare is preloaded in the tip of the cap with its handle running on the outer surface of the scope underneath a plastic sheath (Fig. 3, 4).

The procedure is performed under general anesthesia (in this case, in the supine position). Proper bowel preparation is essential for recognizing the lesion and performing the full-thickness resection.

At first, a standard colonoscopy is performed with identification of the lesion, which is afterwards marked with argon plasma coagulation (ERBE VIO, Tübingen, Germany; forced coagulation effect $1.20 \mathrm{~W}$ ). The endoscope is removed and the FTRD system is 


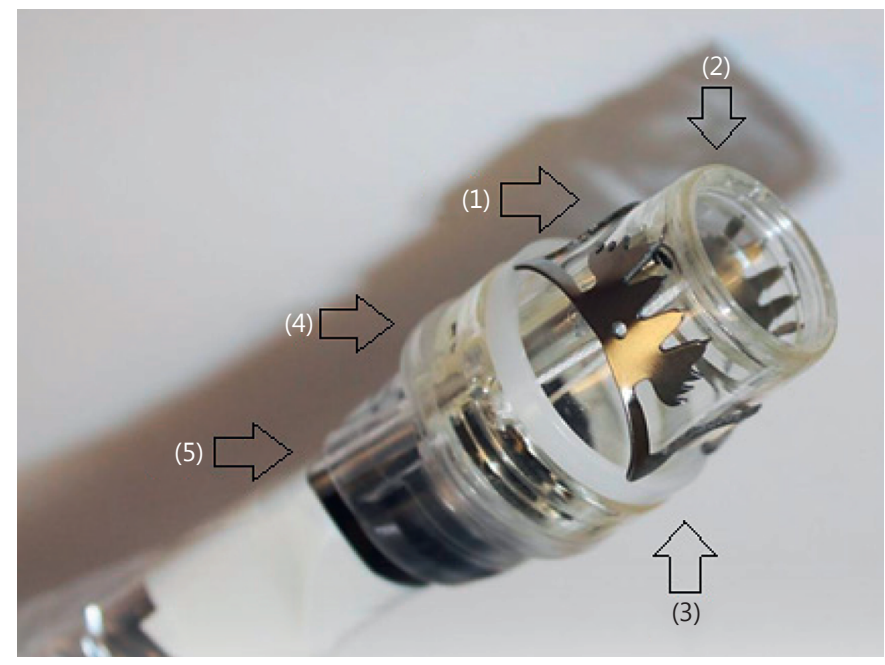

Fig. 4. FTRD application cap (with kind permission of Ovesco Endoscopy): (1) 14-mm over-the-scope clip with additional lateral teeth for improved tissue hold; (2) 23-mm-long and 21-mm-wide cap with preloaded snare; (3) ring application mechanism; (4) endoscope stopper: for endoscopes with an 11.5- to 13.2-mm distal end diameter; (5) snare handle running on the outer surface of the scope underneath the endoscope sleeve.

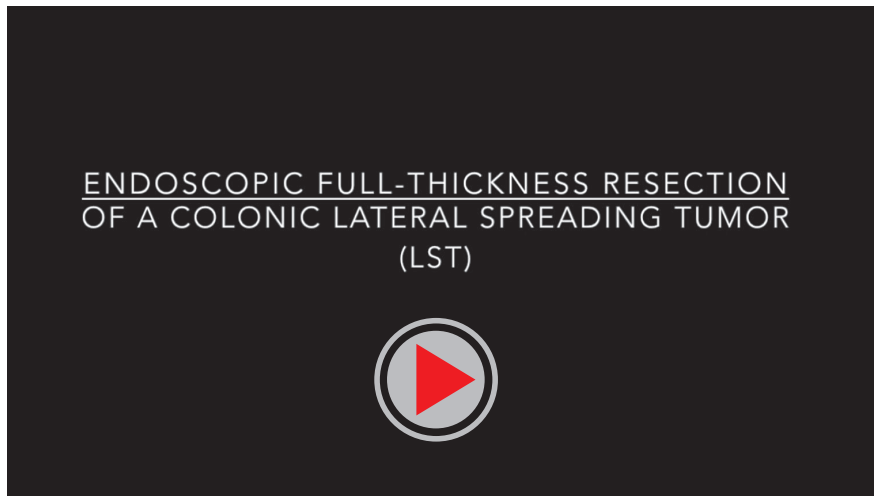

Video 1. EFTR of an LST using the FTRD by Ovesco Endoscopy (for video see www.karger.com/doi/10.1159/000485834).
Fig. 5. Procedural steps. a Marking the lesion before mounting the FTRD System. b, c Grasping of the tissue and mobilizing into the cap. d Application of the clip. e Resection of captured tissue with the integrated HG snare (electrical cut).

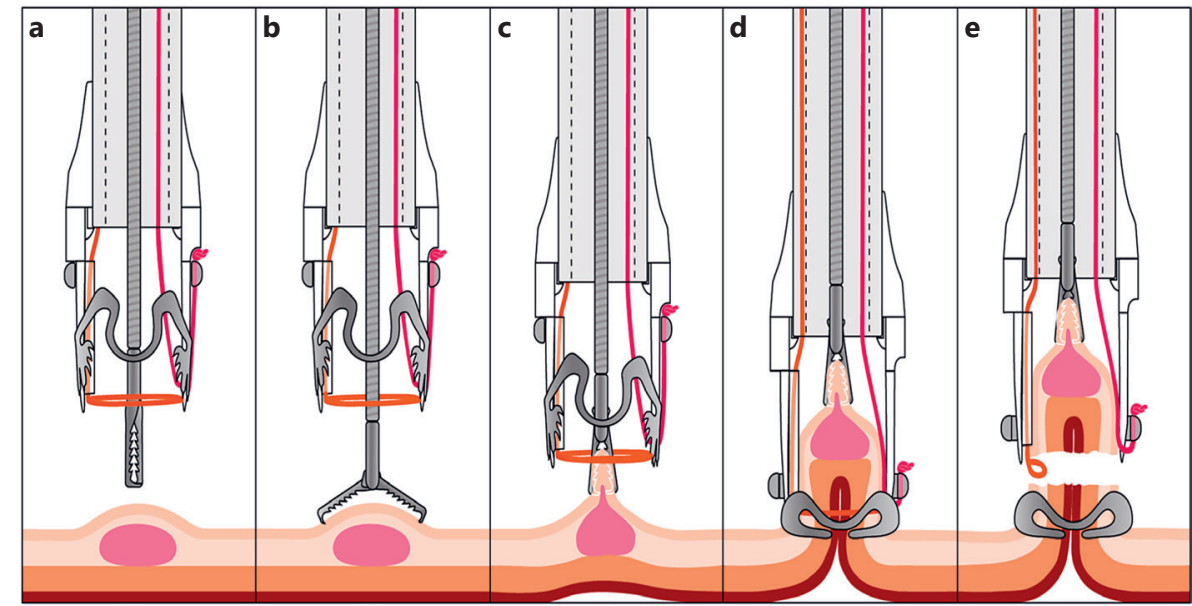

mounted. Then, the endoscope is reinserted, the lesion is grasped centrally and mobilized into the cap using the dedicated grasper. After ensuring that the marked tissue is completely in the cap, the over-the-scope clip is released and the tissue above the clip is quickly resected with the snare (Fig. 5). Suction should be kept to a minimum due to the risk of aspirating adjacent organs. A followup endoscopy is planned within 6 months. In most cases the clip will have fallen off by then. If not and if indicated, it can be removed using a special remover device (DC Clip Cutter, Ovesco Endoscopy), which allows the wires to be cut.

\section{Discussion}

The concept of local full-thickness resection was introduced in the 1980s with transanal endoscopic microsurgery for the removal of rectosigmoid lesions using a rigid endoscopic system. In recent years, EFTR was adapted to flexible endoscopes given the need to resect lesions throughout the colon and rectum. The current major indications for EFTR comprise carcinoid tumors and recur-
Bucalau/Lemmers/Arvanitakis/Blero/ Neuhaus 
rent fibrotic lesions, especially if located at the bottom of the caecum, close to the terminal ileum or in the appendix, which are usually reasons for incomplete resection and perforation during EMR or ESD [5].

The feasibility and effectiveness of this procedure was shown in several case series and 2 retrospective studies, with few complications reported [4, 6, 7]. Recently, the results of the Wall Resect study, the first prospective multicenter trial, were published. The $\mathrm{R} 0$ resection rate in patients with difficult adenomas and early cancer lesions was 77.7 and $44.8 \%$, respectively, with higher efficacy in lesions $\leq 2 \mathrm{~cm}$. Complication rates were more important than expected $(9.9 \%$ total procedure-related adverse events). The 3-month follow-up revealed a recurrent or residual tumor in $15.3 \%$ of patients. The technique was deemed effective by the authors for difficult adenomas $\leq 2$ $\mathrm{cm}$, but was not recommended in early cancers, with further studies being required [8].

Our patient presented a periappendicular LST, with a nonlifting indication. She had already undergone 3 sessions of EMR. EFTR was performed without incident and the immediate follow-up was uneventful (Fig. 6). She was discharged on day 1 after the procedure. The histopathological result showed a tubulovillous adenoma with lowgrade dysplasia (Fig. 7).

\section{Conclusions}

Full-thickness resection can be a tool in the armament of techniques available in difficult cases. Currently suggested to be safe, future studies are needed to investigate the clinical use and applicability of this device, as well as long-term outcomes.

\section{Acknowledgments}

We would like to thank all who made the 35th GEEW 2017 possible, including the doctors, foreign experts, nurses, and auxiliary staff.

\section{Ethics Statement}

The patient provided informed written consent to undergo the procedure.

\section{Disclosure Statement}

The authors have no conflicts of interest to disclose. This original report is not under simultaneous consideration by any other publication.

Endoscopic Full-Thickness Resection of a

Colonic Lateral Spreading Tumor

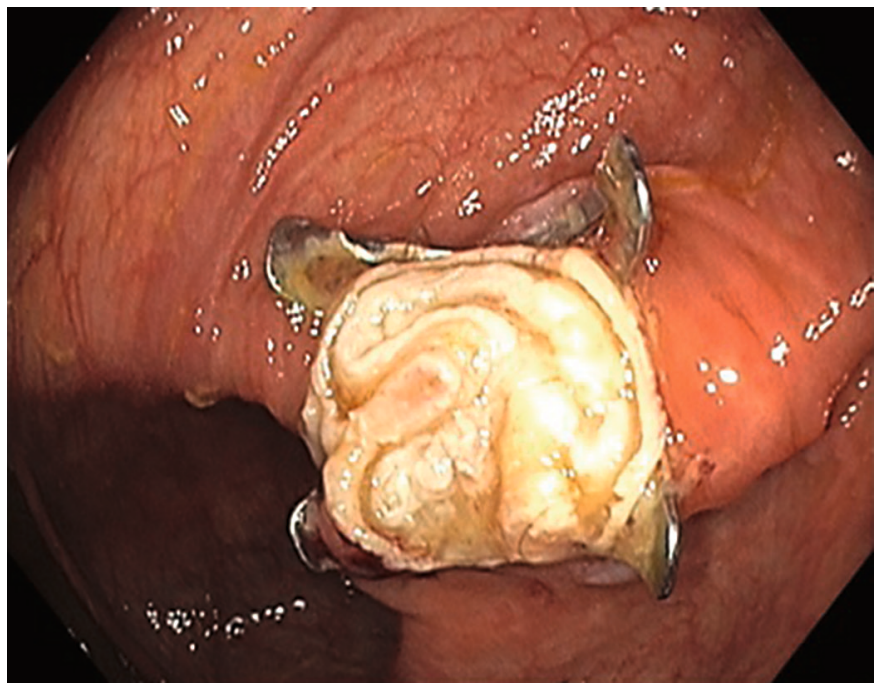

Fig. 6. Image showing all the layers of the colon after full-thickness resection of the LST.

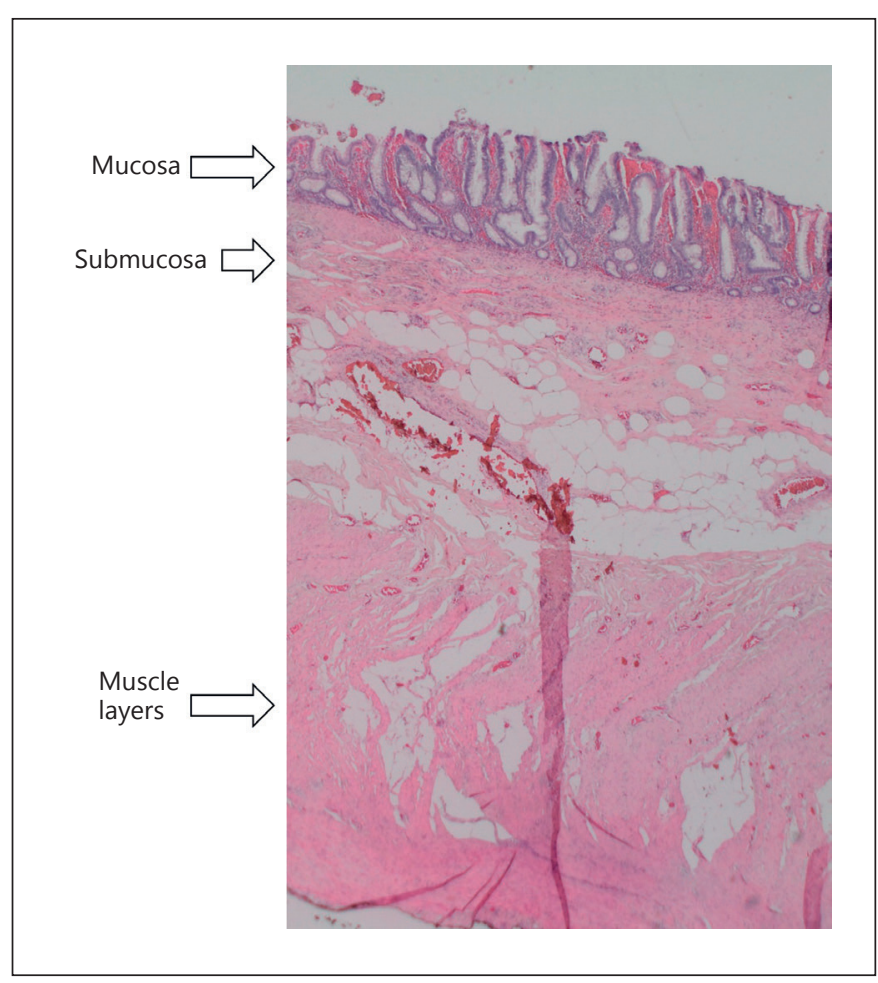

Fig. 7. Histopathological specimen of the LST full-thickness resection. 


\section{References}

-1 Oka S, Tanaka S, Saito Y, Iishi H, Kudo SE, Ikematsu $\mathrm{H}$, Igarashi M, Saitoh $\mathrm{Y}$, Inoue $\mathrm{Y}$, Kobayashi K, Hisabe T, Tsuruta O, Sano Y, Yamano H, Shimizu S, Yahagi N, Watanabe T, Nakamura H, Fujii T, Ishikawa H, Sugihara $\mathrm{K}$ : Local recurrence after endoscopic resection for large colorectal neoplasia: a multicenter prospective study in Japan. Am J Gastroenterol 2015;10:697-707.

2 Pimentel-Nunes P, Dinis-Ribeiro M, Ponchon T, Repici A, Vieth M, De Ceglie A, Amato A, Berr F, Bhandari P, Bialek A, Conio M, Haringsma J, Langner C, Meisner S, Messmann H, Morino M, Neuhaus H, Piessevaux H, Rugge M, Saunders BP, Robaszkiewicz M, Seewald S, Kashin S, Dumonceau JM, Hassan C, Deprez PH: Endoscopic submucosal dissection: European Society of Gastrointestinal Endoscopy (ESGE) guideline. Endoscopy 2015;47:829-854.
3 Hori K, Uraoka T, Harada K, Higashi R, Kawahara Y, Okada H, Ramberan H, Yahagi N, Yamamoto K: Predictive factors for technically difficult endoscopic submucosal dissection in the colorectum. Endoscopy 2014;46: 862-870.

4 Schmidt A, Bauerfeind P, Gubler C, Damm M, Bauder M, Caca K: Endoscopic full-thickness resection in the colorectum with a novel over-the-scope device: first experience. Endoscopy 2015;47:719-725.

$\checkmark 5$ Fujihara S, Mori H, Kobara H, Nishiyama N, Matsunaga T, Ayaki M, Yachida T, Morishita A, Izuishi K, Masaki T: Current innovations in endoscopic therapy for the management of colorectal cancer: from endoscopic submucosal dissection to endoscopic full-thickness resection. Biomed Res Int 2014;2014:925058.
6 Andrisani G, Pizzicannella M, Martino M, Rea R, Pandolfi M, Taffon C, Caricato M, Coppola R, Crescenzi A, Costamagna G, Di Matteo FM: Endoscopic full-thickness resection of superficial colorectal neoplasms using a new over-the-scope clip system: a singlecenter study. Dig Liver Dis 2017;49:10091013.

7 Richter-Schrag HJ, Walker C, Thimme R, Fischer A: Full thickness resection device (FTRD): experience and outcome for benign neoplasms of the rectum and colon (in German). Chirurg 2016;87:316-325.

$>$ Schmidt A, Beyna T, Schumacher B, Meining A, Richter-Schrag HJ, Messmann H, Neuhaus H, Albers D, Birk M, Thimme R, Probst A, Faehndrich M, Frieling T, Goetz M, Riecken B, Caca K: Colonoscopic full-thickness resection using an over-the-scope device: a prospective multicentre study in various indications. Gut 2017;26:581-590. 